Background/introduction Our level 3 GUM clinic has held an integrated young person's clinic (YPC) since 2008. As well as STI testing, we provide all methods of contraception except intrauterine devices, for $<25 \mathrm{~s}$. Maximising the uptake of LARC is recommended as a method of preventing unplanned pregnancy. Previous audits of females attending for contraception have shown that $100 \%$ are offered LARC, but have not included females attending the YPC for other reasons.

Aim(s)/objectives To assess the utility of contraceptive methods of female patients attending and leaving the YPC, as an outcome measure for the effectiveness of contraceptive interventions.

Methods Prospective audit of 100 consecutive females attending the YPC from October 2014.

Results The average age was 19 (14-24). 77(77\%) attended purely for contraception, $11(11 \%)$ for a sexual health check and $12(12 \%)$ for both. $15 / 17(88 \%)$ of those not using contraception and 18/21(86\%) of females using condoms left the clinic with a form of hormone contraception [19/38(50\%) LARC]. On arrival 28(28\%) used oral contraception/Evra and on leaving 42(42\%). On arrival $33(33 \%)$ had LARC and on leaving $48(48 \%)$ had LARC. LARC was offered to all females not already using it, except 2 with complex medical conditions. The commonest reasons for declining were being happy with their current method$17(17 \%)$ and fear of side effects-11(11\%).

Discussion/conclusion The SRHAD proforma used by sexual health clinics only records contraception supplied. Contraception in/out is a better outcome measure of the prevalence of LARC use in a clinic's attendees, and an indicator of holistic sexual healthcare in an integrated YPC.

\section{P244 CHILD SEXUAL EXPLOITATION - REVIEW OF INFORMATION SHARING AND IDENTIFYING PATIENTS AT RISK}

Gillian Fraser*, Beverely Wilson-Brown, Fiona Fargie. Sandyford Initiative, Glasgow, UK

\subsection{6/sextrans-2015-052126.286}

Background/introduction We are a community based, multidisciplinary team providing sexual health care for 8,000 under 20s that attend our service yearly. Child Sexual Exploitation (CSE) is an increasingly recognised problem that affects young vulnerable people across the UK. Information sharing between agencies is an important factor in identifying young people who are involved in CSE and in order to improve our practice, we retrospectively reviewed case notes of those identified as vulnerable to CSE by other agencies.

Aim(s)/objectives To identify: was information shared when a risk of CSE was identified during the sexual health consultation? What is the prevalence of strong and warning signs of CSE in this population of young people attending sexual health services?

Methods Retrospective case note review using our health authority tool for identifying CSE risks.

Results 76 of the136 young people identified had attended our service. 39/76 (51\%) had at least one strong indicator for CSE. $36 / 39$ nine were known to social work. 38/39 had documented information sharing. 11/76 (14\%) had at least one warning indicator and 26/76 (35\%) had no identifiable CSE risk factors. 7/26 had information shared with social work.

Discussion/conclusion Information sharing occurred for almost all patients identified with a strong risk factor for CSE. 49\% of the young people identified by other agencies as at risk did not disclose information that strongly indicated CSE. Incorporation of the BASHH spotting the signs proforma and training to further increase staff awareness is being developed.

\section{P245 A PRAGMATIC PATIENT PATHWAY ENSURING APPROPRIATE SAFEGUARDING DECISIONS FOR CHILDREN WITH GENITAL WARTS}

Margaret Kingston*, Denise Smurthwaite, Sarah Dixon. Central Manchester Foundation Trust, Manchester, UK

\section{$10.1136 /$ sextrans-2015-052126.287}

Background/introduction Children found to have genital warts may present to doctors of various disciplines. The experience and knowledge of these doctors in the diagnosis and management of genital warts, and the need to assess for possible sexual abuse and other sexually transmitted infections (STIs) is variable. The authors have all been contacted for advice regarding the management of these children. In order to streamline this process and ensure that all children are appropriately assessed we developed a clinical algorithm.

Aim(s)/objectives To establish a pragmatic clinical algorithm incorporating safeguarding decisions for the management of children with genital warts.

Methods A group of paediatric, GUM and forensic physicians reviewed the evidence and relevant UK guidelines, consulted with other experts in the field and drafted an algorithm for the management of children with genital warts.

Results An initial algorithm was piloted by the authors and colleagues and sent to authors of relevant UK guidelines for their opinion. The algorithm was then finalised and is now in use in our region. It is presented as a simple flowchart.

Discussion/conclusion Developing this algorithm was complicated by differing views of experts in the field and the unfamiliarity of some doctors other than GUM or forensic physicians in performing genital examinations in children and taking the required tests. We have found this algorithm to be a useful framework for clinical decision making, to support safeguarding decisions and to ensure that the required steps are taken when assessing children with genital warts.

\section{P246 SURVEY OF IMPLANT REMOVALS IN A YOUNG PEOPLE'S SEXUAL HEALTH SERVICE}

F McGregor*, J Hammond, K Jones. Archway Sexual Health Centre, London, UK

\subsection{6/sextrans-2015-052126.288}

Background/introduction A trend for young people (YP) to abandon the contraceptive implant because of intolerable side effects has been noted. YP aged 21 and under attend our Sexual Health (SH) services in London for implants at a rate of 3 inserted to every 2 removed. Replacement of a removed implant is rare: 1 replacement implant to 32 removed. We decided to investigate our clinic population for this trend.

Aim(s)/objectives To identify profile of YP who have implant removals, reasons for removal and formulate on-going support mechanisms.

Methods Staff completed questionnaires on 20 implant removals to ascertain YP profiles and reasons for remova. 
Results

\begin{tabular}{ll}
\hline Age at removal & Range 15-21 yrs, Mean 18.5 yrs, Median 18.5 yrs \\
Length of use & Mean 10.5 months \\
Inserted Pulse & 10 \\
Identified number of reasons & 7 \\
for removal: & 11 \\
$\quad$ Unscheduled bleeding & 18 total \\
Other reasons for removal & 5 \\
Weight gain & 6 \\
Mood changes & 2 \\
Bloating & 3 \\
Headaches & 2 \\
Nausea & 13 \\
Miscellaneous & 5 \\
Received bleeding management & 0 \\
Willing to accept further bleeding & \\
management & 0 \\
Requests for replacement implant &
\end{tabular}

Discussion/conclusion Unscheduled bleeding is the most common reason for premature removal of implants, however many reported multiple reasons. All removals except one required ongoing reliable contraception, but none were willing to reinsert implant. These clients require support to continue this very effective form of contraception: future support includes: Identify who may require monitoring; Stress choices at outset; Offer bleeding management at early stage; Follow up new insertions at 6/52 via telephone support from Health Advisor or Nurse. Ongoing work will include monitoring and surveys on post TOP removals.

\section{P247 QUALITY OF LIFE AND SEXUAL FUNCTION AMONGST WOMEN WITH PERSISTENT GENITAL DISCHARGE OR DERMATOSES}

${ }^{1,2}$ Nina Vora*, ${ }^{3}$ Gary Whitlock, ${ }^{2}$ Nataliya Brima, ${ }^{1}$ Angela Robinson. ${ }^{1}$ Mortimer Marke Centre, London, UK; ${ }^{2}$ University College London, London, UK; ${ }^{3} 52$ Dean Street Clinic, London, UK

\subsection{6/sextrans-2015-052126.289}

Background Existing data on the effect of genital discharge and dermatoses on the quality of life (QoL) and sexual function (SF) in women with genital complaints are limited.

Objectives To study the impact of our specialist clinic for recurrent genital problems on QoL and SF using two validated questionnaires: dermatology life quality index (DLQI) and female sexual function index (FSFI).

Methods All women attending this specialist clinic during 2013 were invited to complete both DLQI and FSFI. Questionnaires were resent six months later or completed at follow-up attendance. Paired questionnaires were analysed using Wilcoxonsigned-rank tests.

Results We received 143 responses: 99 dermatological complaints and 44 discharge complaints. Both complaints have a detrimental effect on QoL (mean \pm SD quality of life scores $8 \cdot 4 \pm 6 \cdot 6$, moderate effect on QoL vs published general population score between 0 and 1 in validation studies). SF was also impaired (score $19.6 \pm 6.9$, vs published general population mean score $30.5 \pm 5.29$ ). 13 patients fully completed DLQI pre and post clinic intervention; there was significant improvement in DLQI scores (median pre-intervention vs post-intervention scores, interquartile range (IQR): $15(12-18)$ vs 8 (6-12),
$P=0.013)$. FSFI scores did not significantly improve (18.55 (16.5-22.5) vs 18.5 (14.0-22.7), $\mathrm{P}=1.000)$.

Discussion/conclusion Both QoL and SF are impaired in many women presenting with recurrent genital complaints. Appropriate assessment and management by senior physicians can significantly improve QoL in these women supporting the role of specialist clinics. There remains significant impairment to SF, warranting research into affordable interventions.

\section{P248 SENSITIVITY OF THE AMSEL'S CRITERIA COMPARED TO THE NUGENT SCORE IN ABSENCE AND IN PRESENCE OF TRICHOMONAS VAGINALIS (TV) AND/OR CANDIDA SPP AMONG WOMEN WITH SYMPTOMATIC VAGINITIS/ VAGINOSIS}

${ }^{1}$ Lucile Belley-Montfort*, ${ }^{2}$ Joel Lebed, ${ }^{3}$ Bonnie Smith, ${ }^{3}$ Melissa Farrell, ${ }^{4}$ Jane Schwebke, ${ }^{5}$ Paul Nyirjesy, ${ }^{6}$ Thomas Davis, ${ }^{6}$ DeAnna Fuller, ${ }^{7}$ Kenneth Fife, ${ }^{8}$ Safedin Sajo Beqaj. 'BD Diagnostics, Québec, QC, Canada; ${ }^{2}$ Planned Parenthood Southeastern Pennsylvania, Philadelphia, PA, USA; ${ }^{3}$ Planned Parenthood Gulf Coast, Houston, TX, USA; ${ }^{4}$ The University of Alabama at Birmingham, Birmingham, AL, USA; ${ }^{5}$ Drexel University, Philadelphia, PA, USA; ${ }^{8}$ Pathology Inc, Torrance, CA, USA; ${ }^{6}$ Wishard Health Services, Indianapolis, IN, USA; ${ }^{7}$ Indiana University, Indianapolis, IN, USA

\subsection{6/sextrans-2015-052126.290}

Background/introduction In a multicenter clinical trial funded by $\mathrm{BD}$, we observed less accurate clinician diagnosis of bacterial vaginosis (BV) based on clinical observations when Trichomonas vaginalis (TV) and/or Candida spp. were also detected by the trial Reference Methods than when only BV was detected.

Aim(s)/objectives To determine the sensitivity of each criterion and of the overall Amsel's criteria (3/4 criteria met), the results of the Amsel's corresponding to the sub-population of specimens that gave a Nugent score of 7-10 were analysed.

Methods Following informed consent, women with symptoms of vaginitis/vaginosis were included in the trial. The four Amsel's criteria and the Nugent score were performed. Evaluation for trichomoniasis by wet mount and culture (InPouch $^{\mathrm{TM}}$ TV, Biomed) were performed. Candida colonies were isolated (BBL ${ }^{\mathrm{TM}}$ Sabouraud Dextrose Agar, Emmons and BBL ${ }^{\mathrm{TM}} \mathrm{CHROMAgar}^{\mathrm{TM}}$ Candida plate, BD) and identified by ITS-2 bi-directional sequencing (Accugenix ${ }^{\circledR}$ ).

Results In total, 269/497 (54.1\%) specimens gave a Nugent score of 7-10. Amongst them, TV and/or Candida spp. were found in 100 specimens (37.2\%). The sensitivity of clue cells, amine test, vaginal $\mathrm{pH}, \mathrm{BV}$ vaginal discharge, and overall Amsel's criteria in absence of TV and/or Candida spp. was $86.3 \%$, $82.7 \%, 91.1 \%, 71.0 \%$, and $84.6 \%$ respectively. In presence of TV and/or Candida spp., the sensitivity was $63.6 \%, 64.0 \%$, $75.0 \%, 42.0 \%$, and $60.0 \%$ respectively ( $\mathrm{p}$ values $\leq 0.0009$ for all comparisons).

Discussion/conclusion The sensitivity of the Amsel's criteria in women with BV decreases when TV and/or Candida spp. are present. The BV vaginal discharge is the least sensitive criterion.

\section{P249 SO WHAT DO WOMEN WANT - ESTABLISHING A WOMEN'S SEXUAL HEALTH SERVICE}

Emma Collins*, Michelle Hawkins. BSUH NHS Trust, Brighton, UK

\subsection{6/sextrans-2015-052126.291}

Introduction Patient and public feedback has highlighted the need for targeted sexual health services for women in our city. 